\title{
Anabases
}

ANABASES Traditions et réceptions de l'Antiquité

16 | 2012

Varia

\section{Regards antiquaires : voyages pittoresques et excursions archéologiques à l'épreuve des visual studies}

Odile Parsis-Barubé

\section{(2) OpenEdition \\ Journals}

\section{Édition électronique}

URL : http://journals.openedition.org/anabases/3991

DOI : 10.4000/anabases.3991

ISSN : 2256-9421

\section{Éditeur}

E.R.A.S.M.E.

\section{Édition imprimée}

Date de publication : 1 octobre 2012

Pagination : 274-279

ISSN : 1774-4296

\section{Référence électronique}

Odile Parsis-Barubé, «Regards antiquaires : voyages pittoresques et excursions archéologiques à l'épreuve des visual studies », Anabases [En ligne], 16 | 2012, mis en ligne le 01 octobre 2015, consulté le 21 octobre 2019. URL : http://journals.openedition.org/anabases/3991; DOI : 10.4000/anabases. 3991

Ce document a été généré automatiquement le 21 octobre 2019

(c) Anabases 


\title{
Regards antiquaires : voyages pittoresques et excursions archéologiques à l'épreuve des visual studies
}

\author{
Odile Parsis-Barubé
}

1 La réflexion qui a fécondé cette recherche a mûri au sein du laboratoire IRHiS (Institut de Recherches Historiques du Septentrion) de l'Université Charles-de-Gaulle-Lille 3 où, depuis 2010, se sont développés deux axes transversaux consacrés, l'un aux cultures visuelles, l'autre à la construction des savoirs et à la circulation des modèles. L'axe « cultures visuelles » a pour vocation première de réunir des chercheurs spécialisés en histoire et histoire de l'art, et intéressés par l'image, les artefacts visuels et les dispositifs de représentation visuelle présents dans toutes les cultures. La thématique iconologique a constitué une plate-forme sur laquelle se sont également retrouvés les historiens et historiens de l'art engagés dans la recherche sur le rôle de l'image dans la construction des savoirs naturalistes et antiquaires. Au sein de ce dispositif, il nous a paru utile d'initier une réflexion sur la possibilité d'ouvrir un autre chantier consacré à l'approche des cultures sensibles dans un champ historiographique - celui de l'histoire de l'antiquarisme - demeuré jusqu'à présent essentiellement centré sur l'analyse des pratiques savantes (philologie, archivistique, collectionnisme, archéologie) mises en œuvre par les érudits des époques classique et romantique.

Depuis maintenant près de quarante ans, la notion de Visual Culture a fait son apparition dans le monde anglo-saxon. Elle a déjà permis le renouvellement d'un certain nombre d'enquêtes, de débats théoriques et de questions portant sur l'omniprésence des dispositifs de visualisation et la création des artefacts visuels (signes, images, décors...) créés par les cultures humaines. Nées aux États-Unis ${ }^{1}$, ces études ont rapidement gagné l'ensemble du continent américain, l'Asie (Inde, Corée), l'Europe centrale, la Scandinavie et l'Europe du Sud. En Allemagne, la Bildwissenschaft s'est développée dans les milieux de l'histoire de l'art érudite (sur des objets ayant trait à la Renaissance et au 
baroque) et non dans celui des cultural studies, ce qui la rend sans doute plus audible en France où l'on est resté longtemps réticent à la forme anglo-saxonne du mouvement. Souvent traduit par " théorie de l'image », elle est en fait une anthropologie de l'image et s'est progressivement construite à partir des années 1920 et des travaux d'Erwin Panofski ${ }^{2}$.

3 L'objectif des visual studies est double. Il est d'abord d'analyser les artefacts (ou créations humaines) qui ont contribué à construire visuellement les cultures historiques, en les saisissant dans la diversité de leurs expressions matérielles ( « images » et « signes » en premier lieu, mais aussi cadres urbains et architecturaux), corporelles (vêtements, tatouages, maquillages, bijoux...) et même immatérielles (idéologies religieuses ou politiques par exemple). Il est ensuite d'appréhender leur impact culturel à travers les traces scripturaires des impressions visuelles qu'ils ont laissées ou suscitées, des habitus que leur observation a créés, des émotions et des significations dont les différentes sociétés les ont investies à travers le temps. Les sources sollicitées relèvent, dans ce domaine, des récits de voyage, discours scientifiques, utopies ou écrits de fiction. Cette approche ne privilégie donc pas a priori l'aspect esthétique, la maîtrise technique ou la notion d'œuvre singulière dans l'étude des éléments visuels d'une culture. Elle s'intéresse avant tout à leur langage et à leurs codes ainsi qu'à tous les aspects de leur production, de leur diffusion, de leur circulation, de leur réception et de leur impact, tant individuel que collectif. En d'autres termes, il s'agit non seulement d'étudier la nature des cultures visuelles mais aussi leurs pratiques et leur «fabrique » dans l'histoire et dans les sociétés. L'axe de recherche sur les cultures visuelles se place donc délibérément dans une perspective historique, replaçant ses objets d'étude dans leur contexte et tentant d'en appréhender les évolutions, tout en pratiquant une approche pluridisciplinaire de ceux-ci.

Nous voudrions proposer, à titre exploratoire, un certain nombre de pistes de réflexion sur la place de la visualité dans la culture antiquaire en France au moment où, entre Lumières et romantisme, se redéfinissent la culture du collectionnisme ainsi que les enjeux moraux, esthétiques et idéologiques du voyage en France.

5 La question de l'avènement de l'image dans la culture antiquaire de l'âge classique n'est certes pas nouvelle dans l'historiographie contemporaine de la réception de l'Antiquité. En 1992, Françoise Choay reconstituait les étapes qui, de Peiresc à Caylus en passant par Montfaucon, jalonnèrent, aux XVII et XVIII ${ }^{e}$ siècles, l'élaboration de ces musées d'images que constituaient les recueils d'antiquités ${ }^{3}$. Ce constat de l'importance croissante de l'illustration dans le travail des antiquaires, s'accompagne de celui du primat du témoignage visuel enregistré in situ par le dessin sur l'autorité des textes ${ }^{4}$. L'affirmation de l'observation directe comme fondement de la démarche comparative à l'heure où s'impose l'idée d'une homologie de méthode entre antiquarisme et naturalisme entre en résonance avec des interrogations plus contemporaines sur la culture de la visualité.

Les récents travaux menés au sein d'IRHiS par Charlotte Guichard sur le rôle de l'image dans la construction des savoirs antiquaires ont montré l'importance du visual turn qui, au milieu du XVIII ${ }^{e}$ siècle, a progressivement transformé les relations entre artistes et amateurs et infléchi le rapport à l'antique de ces deux catégories 5 . S'appuyant sur l'exemple de Caylus, elle montre comment "l'expérimentation de l'objet », largement explicitée par le célèbre collectionneur dans sa correspondance, et fondement du Recueil d'antiquités qu'il publie à partir de 1752 , contribue au dessin d'un «instant 
perceptif ${ }^{6} »$ où, dans l'exaltation de la découverte, se dévoile le rôle du plaisir visuel dans la construction de l'expérience esthétique et de l'expertise archéologique.

Charlotte Guichard, qui a travaillé sur la figure de l'amateur d'art, a distingué deux moments-clés de l'intensification du plaisir visuel et de son épanchement dans une poétique finalement convenue de l'attente, de l'inquiétude et de l'enthousiasme: le « déballage » des œuvres et «l'arrangement » de la collection. Nos propres recherches, sur la culture antiquaire de l'époque romantique ${ }^{7}$, nous ont amenée à appréhender le problème sous un angle un peu différent, qui est celui de la dynamique recherche/ découverte du vestige in situ.

8 La période qui s'ouvre au milieu du $\mathrm{xVIII}^{\mathrm{e}}$ siècle avec le resserrement progressif de la curiosité antiquaire sur les antiquités nationales et provinciales et se clôt vers 1860 sur l'assomption de l'histoire locale, tout à la fois comme genre historiographique et pratique culturelle dominante des élites provinciales, est également marquée par une redéfinition des enjeux culturels du voyage. L'inventaire archéologique qui, depuis le milieu du XVIII e siècle s'est inscrit dans l'éventail des pratiques marquées par le primat des sciences de l'observation, se fait peu à peu rattraper par la quête du pittoresque. Dans la France du premier XIX ${ }^{e}$ siècle, il s'inscrit clairement dans une tension entre les impératifs statisticiens liés au voyage d'enquête et la poésie rétrospective propre à la culture viatique de l'époque romantique ${ }^{8}$. Entre le modèle du "voyage d'impressions " théorisé en 1820 par Charles Nodier et celui du compte rendu d'excursion archéologique diffusé par l'antiquarisme institutionnalisé sous la monarchie de Juillet, se déploie tout une gamme de pratiques spectatoriales et d'émotions visuelles qui conduisent à interroger la place de l'expérience sensible dans les pratiques savantes de reconquête du passé alors à l'œuvre. Ce jeu concurrentiel des nouvelles «mécaniques du regard» est aussi traversé par les enjeux esthétiques qui, entre 1750 et 1850 , accompagnent l'évolution de l'imaginaire des temps historiques, enjeux dans lesquels entre notamment la question de la part respective de l'antique et du médiéval dans le processus d'invention du paysage archéologique.

Récits de voyages pittoresques illustrés et comptes rendus d'excursions archéologiques constituent donc, au sein des écrits sur l'antique laissés par les XVIII et XIX siècles, un corpus à retravailler. Si les premiers ont été abondamment étudiés pour ce qu'ils révèlent du rôle de la lithographie dans la diffusion de l'esthétique du paysage archéologique $^{9}$ et les seconds pour leur apport à la connaissance des méthodes de l'antiquarisme romantique ${ }^{10}$, l'un et l'autre mériteraient d'être repris dans le cadre d'une étude systématique des données qu'ils sont susceptibles de livrer sur les liens entre antiquarisme et culture de la visualité.

Quelques travaux liminaires nous incitent à penser que l'on pourrait avec profit appliquer aux études antiquaires le concept de «mécanique du regard» qu'Alain Corbin a si judicieusement intégré dans le champ de l'anthropologie du paysage ${ }^{11}$. Voyages pittoresques - devenus « romantiques » sous la plume de Taylor et Nodier - et excursions archéologiques relèvent de deux logiques d'appréhension de l'espace qui, pour n'être pas systématiquement opposées, n'en apparaissent pas moins intrinsèquement divergentes. Les premiers, qui, à l'invitation de Nodier, privilégient la posture du voyageur curieux et avide de souvenirs sur celle du voyageur savant, relèvent de cette propédeutique du regard mise en œuvre dans les jardins anglais de la seconde moitié du XVIII ${ }^{e}$ siècle et qui est quête de la surprise au détour du chemin. Cette logique ordonne le séquençage de l'espace parcouru selon une succession d'impressions 
visuelles. Sur la route qui conduit de Pont d'Ain à Cerdon, Charles Nodier invite l'œil à s'adapter aux sinuosités et aux dénivelés. Dans la succession des échappées offertes par les anfractuosités du rocher, s'exerce une mécanique du regard qui est, tour à tour, appel à se perdre dans l'immensité des lointains et invitation au balayage visuel avec, toujours présent à l'arrière plan, le modèle pictural : « La route, élégamment boisée [...] laisse à peine entrevoir, d'espace en espace, quelques profondes échappées de plaines qui baignent des eaux calmes et limites, et que ferment des montagnes chargées d'ombrages et de cultures. Après les beaux paysages de Neuville sur l'Ain, dont les lignes se cadencent avec autant d'art que les compositions du Lorrain, peu à peu la vallée se creuse à la gauche du voyageur ${ }^{12} \ldots$.. . Avant d'être observation minutieuse du vestige archéologique, le regard du voyageur pittoresque est d'abord invitation au dépassement du réel. Les monuments, sous la plume de Nodier, deviennent le motif d'une théorie du souvenir dans laquelle l'histoire n'est plus que jaillissement spontané d'images : «À leur vue, écrit-il, tous les souvenirs des jours écoulés se réveillent : les siècles entiers avec leurs mœurs, leurs croyances, leurs révolutions, la gloire des grands capitaines semblent apparoître dans ces solitudes ${ }^{13}$.» Primat des impressions visuelles qui fait de l'histoire une affaire d'imagination et s'oppose à l'exigeante discipline définie en 1824 par les antiquaires de Normandie, pour lesquels la connaissance historique ne saurait advenir qu'au prix du croisement de plusieurs regards scientifiques et techniques, dont Henri de Magneville, dans le premier volume des Mémoires de la jeune société savante créée en 1824 imagine ainsi le partage : «L'érudit fixera les époques historiques par l'examen des médailles et des inscriptions; l'architecte et le statuaire indiqueront les beautés ou les bisarreries (sic) des formes, des ornemens et des sculptures; le géomètre et le physicien les difficultés vaincues dans la construction; le minéralogiste et le géologue feront connaître la nature, le nom, l'origine des matériaux $[. . .]^{14}$.» Le regard unifiant du voyageur pittoresque reconstitue au contraire la totalité $d u$ "tableau », cherche la coïncidence visuelle avec le modèle pictural : Charles Hédouin, s'arrêtant sur l'émotion suscitée par le panorama de Guémy, dans le Boulonnais, peut ainsi écrire que « du point où elle est placée, la vue embrasse un horizon immense, animé par des villages, des champs, des coteaux, et par la mer, qui ajoute encore au charme et à la grandeur d'un tableau digne d'exercer le talent d'un Bertin ou d'un Constable ${ }^{15}$ ». Procédé poétique qui autorise l'expression littéraire de l'émotion ressentie devant les paysages, la métaphore picturale est aussi inhérente à la structure même de l'album pittoresque où les notices rédigées sont souvent le complément des planches gravées qui l'illustrent. Elle tient également au fait que, dans un certain nombre de cas, les auteurs qui signent textes et dessins sont eux-mêmes des peintres ${ }^{16}$.

11 S'il emprunte au genre voyage pittoresque un certain nombre de ses codes, le compte rendu d'excursion archéologique qui revendique très tôt une parenté avec le voyage d'observation, vient enrichir considérablement la gamme des modes sensibles d'appréhension du territoire que le premier XIX siècle a déclinés : «Nous explorions ensemble les environs, nous allions parfois fort loin visiter de nos yeux et toucher de nos mains les découvertes signalées à notre attention ${ }^{17}$ ", écrit le vice-président de la Commission des antiquités du Pas-de-Calais en 1871. Les comptes rendus que publient les sociétés savantes de l'époque oscillent entre deux genres : l'archéologie descriptive et le récit de voyage. Il faut donc s'attacher aux marques de surface dont les textes sont porteurs pour authentifier les véritables sorties sur le terrain, traquer les indices qui laissent entrevoir les conditions matérielles du déplacement et trahissent les 
sensations physiques éprouvées par le voyageur. Encore fortement marqué par la culture du cheminement propre aux mobilités réduites de l'Ancien Régime, le premier $\mathrm{XIX}^{\mathrm{e}}$ siècle reste celui des progressions pénibles et des jouissances visuelles conquises de haute lutte. La pénibilité physique du cheminement qui mène au site archéologique participe d'une image convenue du parcours initiatique au terme duquel la contemplation du vestige s'offre comme une récompense. Temps fort de jouissances visuelles, le récit d'excursion archéologique concourt à la promotion du panorama. La vision synoptique offre, de toute évidence, des commodités particulières à l'exposé des données objectives que l'antiquaire souhaite livrer à son lecteur. À Carnac, Mérimée qui s'attache à reconstituer avec une précision de géomètre la configuration et l'orientation des alignements, recommande à l'observateur de s'élever afin d'embrasser de la vue la portion la plus large possible de l'ensemble. La vue panoramique, dès lors, devient la clé qui peut donner sens au paysage: «De loin, surtout dans un endroit élevé, l'œil, découvrant l'ensemble du monuments, juge avec plus d'exactitude de sa forme générale ${ }^{18}$. Elle ouvre aussi à la gamme des impressions visuelles propres à la vue panoptique: «Du haut des dolmens les plus rapprochés d'Erdeven, la vue de ces immenses allées offre un spectacle imposant et solennel. Lorsque je montai sur le toit d'un de ces dolmens, le soleil était sur son déclin et le ciel et la mer, à l'ouest se coloraient d'une lumière empourprée. Sur ce fond éclatant, les peulvens de Kerzerho se détachaient vigoureusement en noir, tandis que du côté de l'étang, le reste des avenues, fortement éclairé, montrait les pierres blanches et brillantes, tranchant fortement sur le sol couvert d'ajoncs et d'herbes sombres ${ }^{19}$. »

Ces quelques exemples ne constituent qu'un aperçu des ressources que la littérature viatique, dans les différentes déclinaisons que le premier $\mathrm{XIX}^{\mathrm{e}}$ siècle lui a données, recèlent en matière d'histoire de la culture de la visualité. Cette dernière ne constituant, au demeurant, que l'un des volets d'une étude plus globale des approches sensibles des territoires archéologiques pratiquées par les antiquaires de l'époque romantique.

\section{NOTES}

1. W. J. Th. Mitchell, Iconologie: image, texte, idéologie [1 ${ }^{\text {re }}$ éd. Chicago, 1986], Paris, Les Prairies ordinaires, 2009 ; «An interview with Michael Ann Holly» (2001), in M. DIKovitsKAYA, Visual Culture. The Study of the Visual after the Cultural Turn, Cambridge, The MIT Press, 2005 ; M. BAXANDALL, Painting and Experience in the Fifteen-Century Italy, Oxford, Oxford University Press, 1972 [trad. fr. L'œil du Quattrocento, Paris, 1985]; S. ALPERS, The Art of Describing, Chicago, Chicago University Press, 1983 [trad. fr. L'art de dépeindre, Paris, Gallimard, 1990].

2. E. PANOFSKY, La perspective comme forme symbolique et autres essais [1 ${ }^{\text {re }}$ éd. 1927], trad. G. Ballangé, Paris, Minuit, 1975 ; Essais d'iconologie. Les thèmes humanistes dans l'art de la Renaissance, trad.

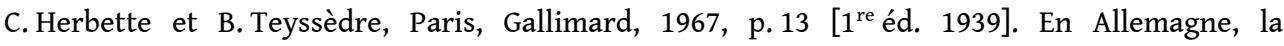
Bildwissenschaft s'est développée plus récemment autour de deux auteurs : H. BELTING, Image et culte. Une histoire de l'art avant l'époque de l'art, Paris, Cerf, 1998; L'histoire de l'art est-elle finie? Histoire et archéologie d'un genre, Paris, éditions J. Chambon, 1999; Pour une anthologie des images, 
Paris, Gallimard, 2003. Et H. BREDEKAMP, La Nostalgie de l'Antique. Statues, machines et cabinets de curiosités, Paris, New York et Amsterdam, 1996 ; Stratégies visuelles de Thomas Hobbes : le Léviathan, Paris, éditions de la Maison des Sciences de l'Homme, 2003 ; Les coraux de Darwin : premiers modèles de l'évolution et tradition de l'histoire naturelle, Dijon, Presses du réel, 2008 [trad. de l'éd. allemande, Berlin, 2003]. En France, on se référera aux travaux de Ph. DEsColA, Par delà nature et culture, Paris, Gallimard, 2006 qui fait une anthropologie de la mise en image dans toutes les civilisations connues ainsi qu'à ceux de Louis Marin, notamment De la représentation, Paris, Seuil, 1993 ; Études sémiologiques : écritures, peintures, Klincksieck, 2005 ; Des pouvoirs de l'image, Paris, Seuil, 1998.

3. F. сноАу, L'allégorie du patrimoine, Paris, Seuil, « La couleur des idées », 1992, p. 60-64.

4. Nous renvoyons ici à la correspondance de Nicolas Peiresc, en particulier à ses Lettres à Cassiano dal Pozzo (1626-1637) dans l'édition qu'en ont donnée J.-F. LHôTE et D. JOYAL, Clermont-Ferrand, Amphio, Adosa, 1989.

5. Ch. GUICHARD, Les amateurs d'art en France au XVIII siècle, Paris, Seyssel, Champ Vallon, 2008, p. $190-217$.

6. Expression empruntée à M. BAXANDALL, Formes de l'intention. Sur l'explication historique des tableaux, Paris, J. Chambon, 1991, p. 163 [éd. anglaise, 1983].

7. La province antiquaire. L'invention de l'histoire locale en France (1800-1870), Paris, СTHS, 2011.

8. O. PARSIS-BARUBÉ, «De l'itinéraire muséographique au paysage archéologique. Mutation des objets du pittoresque dans la culture du voyage en France au cours de la seconde moitié du XVIII ${ }^{\mathrm{e}}$ siècle ", in J.-P. LeTHUILLIER, O. PARSIS-BARUBÉ (dir.), Le Pittoresque. Métamorphoses d'une quête dans l'Europe moderne et contemporaine, Paris, Classiques Garnier, 2012.

9. C. JEANJEAN-BECKER, Les récits illustrés de voyages pittoresques de 1770 à 1852, DEA de méthode de l'archéologie, de l'histoire et de l'histoire de l'art, ss la dir. de Jean-Michel Léniaud, Paris, EPHE, juin 1998, ex. dactyl., $137 \mathrm{p}$.

10. Voir notre ouvrage La province antiquaire. L'invention de l'histoire locale en France (1800-1870), Paris, CTHS, 2011.

11. A. CORBIN, L'homme dans le paysage, Paris, Textuel, 2001.

12. Voyages pittoresques et romantiques dans l'ancienne France par MM. Ch. Nodier, J. Taylor et Alph. De Cailleux, Franche-Comté, Paris, Didot l'Aîné, 1825, p. 45-46.

13. Ibidem, p. 2.

14. Mémoires de la Société des Antiquaires de Normandie, I, 1824, p. v.

15. Ch. HÉDouIN, Souvenirs historiques et pittoresques du département du Pas-de-Calais, Paris, 1826-1827, Lettre XVII, n. p.

16. Tel est par exemple le cas du Boulonnais Hédouin, cité plus haut ou encore de Thiénon, auteur d'un Voyage pittoresque dans le bocage de la Vendée, Paris, Didot, 1817.

17. Bulletin de la Commission des antiquités du Pas-de-Calais, t. III, p. 135.

18. Pr. MÉRIMÉE, Notes d'un voyage dans l'Ouest de la France, présentées par Pierre-Marie AUZAS, Paris, Adam Biro, 1989, p. 115.

19. Ibidem, p. 116. 


\section{AUTEUR}

\section{ODILE PARSIS-BARUBÉ}

Université Charles-de-Gaulle-Lille 3, IRHis (UMR CNRS 8529) 